\title{
Utilização de bactérias ácido-lácticas isoladas do trato intestinal de tilápia-do-nilo como probiótico
}

\author{
Adolfo Jatobá(1), Felipe do Nascimento Vieira ${ }^{(1)}$, Celso Buglione Neto ${ }^{(1)}$, Bruno Corrêa Silva ${ }^{(1)}$, \\ José Luís Pedreira Mouriño(1), Gabriela Tomas Jerônimo(2), Geovana Dotta(2) ${ }^{(2)}$ Maurício Laterça Martins ${ }^{(2)}$
}

(1)Universidade Federal de Santa Catarina (UFSC), Departamento de Aqüicultura, Laboratório de Camarões Marinhos, Beco dos Coroas, Barra da Lagoa, CEP 88062-601 Florianópolis, SC. E-mail: adjatoba@yahoo.com.br, felipenvieria@yahoo.com.br, celsocebneto@yahoo.com.br, bcs85@hotmail.com, morino@Icm.ufsc.br (2)UFSC, Departamento de Aqüicultura, Laboratório de Pesquisas em Sanidade de Organismos Aquáticos, Rodovia SC 404, Km 3, CEP 88040-900 Florianópolis, SC. E-mail: gabrielatj@hotmail.com, geovanadotta@hotmail.com, mlaterca@cca.ufsc.br

Resumo - O objetivo deste trabalho foi isolar bactérias ácido-lácticas do intestino de tilápias-do-nilo, e avaliar seu potencial probiótico. Foram isoladas cepas de bactérias ácido-lácticas, e foi avaliada a inibição aos patógenos in vitro. As cepas com os melhores resultados foram identificadas e utilizadas no experimento de colonização do trato intestinal de tilápias-do-nilo, via suplementação na dieta, em delineamento inteiramente ao acaso, com três tratamentos e quatro repetições. Foram avaliados: o total de bactérias, as bactérias ácidolácticas, Vibrio ssp. e Pseudomonas ssp. A cepa com melhor resultado foi utilizada na infecção experimental, em delineamento inteiramente ao acaso, em esquema fatorial $2 \times 3$ : dieta suplementada com a cepa e dietacontrole; e os peixes não submetidos à injeção, peixes submetidos à injeção de solução salina e à injeção de Enterococcus durans, com três repetições. Foram avaliados os parâmetros hematológicos. As duas cepas identificadas foram: Lactobacillus plantarum e Lactobacillus brevis, que colonizaram o trato intestinal de tilápias, contudo L. plantarum teve menor número total de bactérias e de Pseudomonas ssp. Foi observado maior número total de eritrócitos, trombócitos, leucócitos, linfócitos, neutrófilos e monócitos, em peixes alimentados com L. plantarum e submetidos à injeção de E. durans. O L. plantarum tem efeito probiótico e melhora o sistema imune das tilápias.

Termos para indexação: Enterococcus durans, Lactobacillus plantarum, Oreochromis niloticus, hematologia, infecção experimental.

\section{Lactic-acid bacteria isolated from the intestinal tract of Nile tilapia utilized as probiotic}

\begin{abstract}
The objective of this work was to isolate lactic-acid bacteria from the intestines of Nile tilapia, and to assess their potential as probiotic. Strains of lactic-acid bacteria were isolated, and inhibition against pathogens was evaluated in vitro. Strains with best results were identified and used in tilapia intestinal tract colonization experiment through supplementation in the diet, in a completely randomized design, with three treatments and four replicates. Total number bacteria, lactic-acid bacteria, Vibrio ssp. and Pseudomonas ssp. were evaluated. The strain with best result was used for experimental infection, in a completely randomized design, in factorial arrangement $2 \times 3$ : diet supplemented with strain and control diet; and fish not submitted to injection, fish submitted to injection of saline solution, and fish submitted to injection of Enterococcus durans, with three replicates. Hematological parameters were evaluated. Two strains were identified as Lactobacillus plantarum and Lactobacillus brevis, which colonized fishes' intestinal tract. However, L. plantarum had the lowest number of total bacteria and of Pseudomonas ssp. Greater number of red blood cells, thrombocytes, leukocytes, lymphocytes, neutrophils and monocytes were observed in fish fed with L. plantarum and submitted to injection of $E$. durans. L. plantarum has probiotic effect on Nile tilapias and improve their immune system.

Index terms: Enterococcus durans, Lactobacillus plantarum, Oreochromis niloticus, hematology, experimental infection.
\end{abstract}

\section{Introdução}

No cultivo de tilápias, as bactérias Aeromonas spp., Pseudomonas fluorescens, Vibrio anguillarum, Flavobacterium columnare, Edwardsiella tarda, Streptococcus spp. e Enterococcus sp. são freqüente- mente isoladas de surtos de mortalidades (Plumb, 1999; Moraes \& Martins, 2004). As perdas na produção, em razão de epidemias bacterianas na piscicultura, excedem 10 milhões de dólares (Shoemaker \& Klesius, 1997). 
Para o controle das enfermidades bacterianas, os antibióticos são comumente utilizados (Planas et al., 1994). Porém, o uso inapropriado desses quimioterápicos pode provocar a seleção de algumas cepas patogênicas resistentes (Vázquez et al., 2005), além de ser fonte de poluição ambiental (Boyd \& Massaunt, 1999).

Os probióticos são uma alternativa para reduzir a utilização de antibióticos na aqüicultura. Gatesoupe (1999) define probiótico para aqüicultura como "células microbianas que são adicionadas de uma maneira que entrem no trato digestivo dos animais, mantendo-se vivas, com o objetivo de melhorar a saúde do animal". Os probióticos podem agir na prevenção de enfermidades, e diminuir a carga bacteriana, por exclusão competitiva ou produção de substâncias inibidoras, e podem estimular o sistema imunológico dos animais, além de produzir enzimas digestivas suplementares (Verschuere et al., 2000).

O uso de bactérias ácido-lácticas como probióticos se deve à sua capacidade de inibir o crescimento de bactérias patogênicas pela produção de compostos antibacterianos, como: bacteriocinas, peróxido de hidrogênio, ácido láctico e reuterim (Fuller, 1989). Kumar et al. (2008) trabalharam com Bacillus subtilis isolados de carpas e verificaram seu efeito imunoestimulante em Labeo rohita. Vieira et al. (2007) isolou uma bactéria ácido-láctica de camarões marinhos - Litopenaeus vannamei - adultos e observaram seu efeito probiótico pelo aumento da resistência de larvas da mesma espécie à infecção por Vibrio harveyi. Assim, o isolamento e a seleção de bactérias benéficas do trato intestinal de tilápias constituem-se importante estratégia para o desenvolvimento de probióticos para essa espécie.

O objetivo deste trabalho foi isolar cepas de bactérias ácido-lácticas presentes no intestino de tilápia-do-nilo e verificar seu potencial probiótico.

\section{Material e Métodos}

O experimento foi conduzido no Laboratório de Camarões Marinhos, do Departamento de Aquicultura, em conjunto com o Laboratório de Diagnóstico e Patologia em Aqüicultura, do Departamento de Aqüicultura da Universidade Federal de Santa Catarina, de agosto de 2006 a março de 2007.
Para o isolamento de bactérias ácido-lácticas, os intestinos de sete tilápias saudáveis $(232,0 \pm 42,7 \mathrm{~g})$ foram dissecados e macerados com solução salina estéril $0,65 \%$ de $\mathrm{NaCl}$ (SSE). Foram realizadas duas diluições seriadas fator 1:10, e foram semeadas em placas de Petri com meio de cultura ágar Man Rogosa Sharpe (MRS) modificado por Ramírez et al. (2006). As placas foram incubadas por 48 horas, em estufa a $35^{\circ} \mathrm{C}$. Após a incubação, as colônias que se desenvolveram no meio de cultura foram identificadas morfologicamente pelo método de coloração de Gram. As colônias de interesse (cocos e bacilos gram-positivos) foram semeadas em novo meio de cultura ágar MRS, para isolamento por esgotamento em placa.

O experimento de inibição in vitro de bactérias ácido-lácticas isoladas contra patógenos foi realizado em delineamento inteiramente ao acaso, com três repetições. Os patógenos utilizados foram Vibrio harveyi, $V$. anguilarum, $V$. alginolyticus, Enterococcus durans, Micrococcus luteus e Escherichia coli. Utilizouse o método de Tagg \& Mc Given (1971), adaptado por Ramírez et al. (2006), pelo qual cepas de bactéria ácido láctica foram semeadas em placas de Petri com meio ágar MRS. Essas cepas foram isoladas anteriormente e incubadas a $35^{\circ} \mathrm{C}$, por 48 horas. Em seguida, foram retirados três discos de ágar $\mathrm{MRS}$, de $0,8 \mathrm{~cm}$ de diâmetro, com as cepas de bactérias ácido-lácticas, e colocados em meio de cultura ágar triptona de soja (TSA), infestado com um dos patógenos. Essas placas foram incubadas a $30^{\circ} \mathrm{C}$ por 24 horas. $\mathrm{O}$ processo foi repetido para todas as cepas de bactérias ácido-lácticas isoladas.

A inibição foi observada pelo halo produzido ao redor dos discos de ágar MRS, impregnados com as cepas de bactérias ácido-lácticas. Para comparação, foram realizados antibiogramas com magnamicina, eritromicina, enrofloxacina e oxitetraciclina contra as mesmas bactérias patogênicas. As duas cepas, que apresentaram os maiores halos de inibição in vitro, em relação aos patógenos, foram identificadas bioquimicamente com o kit API $50 \mathrm{CH}$ e foram selecionadas para o experimento de colonização do trato intestinal de tilápias-do-nilo, via suplementação na dieta.

Para o preparo da dieta experimental, a ração foi aspergida com as cepas de bactérias ácido-lácticas, crescidas em meio de cultura MRS, na concentração de $1 \times 10^{8} \mathrm{UFC} \mathrm{mL} \mathrm{mL}^{-1}$, na proporção de $100 \mathrm{~mL} \mathrm{~kg}^{-1}$ de ração comercial - Guabi $32 \%$ de proteína bruta, extrusada. 
A mistura foi incubada durante 24 horas, a $35^{\circ} \mathrm{C}$, em recipiente hermeticamente fechado. Após esse período, os recipientes com as rações foram abertos e secados em estufa por 24 horas, a $35^{\circ} \mathrm{C}$. Esse procedimento foi repetido separadamente para as duas cepas de bactérias selecionadas in vitro. A ração do tratamento-controle foi aspergida apenas com meio de cultura MRS estéril. Para a quantificação de bactérias ácido-lácticas na ração, foram realizadas cinco diluições seriadas fator 1:10. As diluições $10^{-3}, 10^{-4}$ e $10^{-5}$ foram aspergidas em meio de cultura ágar MRS modificado (Ramírez et al., 2006). A contagem final de bactérias ácido-lácticas, nas rações suplementadas com bactérias probióticas, foi de $1 \times 10^{8} \mathrm{UFC} \mathrm{g}^{-1}$, para ambas as cepas.

Para o experimento de colonização do trato intestinal de tilápias, pelas bactérias ácido-lácticas, foram utilizadas 12 tilápias $(211,0 \pm 38,6$ g) divididas em 12 aquários de $100 \mathrm{~L}$, com aeração e filtro biológico. Foram utilizados três tratamentos - duas cepas de bactérias ácido-lácticas e o controle -, com quatro repetições, em delineamento inteiramente ao acaso. Os peixes foram alimentados duas vezes ao dia, à vontade. A temperatura da água durante o experimento foi de $22,4 \pm 2,3^{\circ} \mathrm{C}, \mathrm{pH} 7,1 \pm 0,4$ e oxigênio dissolvido, $4,3 \pm 0,6 \mathrm{mg} \mathrm{L}^{-1}$.

No quarto dia do experimento, suspendeu-se a alimentação e, após 36 horas de jejum, foram retirados os intestinos com assepsia para pesagem e maceração com o mesmo volume de solução salina estéril. Foram realizadas cinco diluições seriadas fator 1:10 em tubos de ensaio com solução salina e aspergidas em placas de Petri com meio de cultura TSA, ágar MRS, ágar tiossulfato citrato bile sacarose (TCBS) e ágar cetrimide, para contagem de bactérias totais, bactérias ácido-lácticas, Vibrio ssp. e Pseudomonas ssp., respectivamente.

Para a infecção experimental, foi utilizada a cepa que apresentou os melhores resultados na colonização do trato intestinal de tilápias. Foram utilizadas 54 tilápias $(182,3 \pm 44,5 \mathrm{~g})$ divididas em 18 tanques com capacidade para $250 \mathrm{~L}$, com aeração e filtro biológico, em delineamento inteiramente ao acaso, em esquema fatorial $2 \times 3$ : dieta suplementada com a cepa de bactéria ácido-láctica e dieta-controle e peixes não submetidos à injeção, peixes submetidos à injeção de $500 \mu \mathrm{L}$ de SSE e peixes submetidos à injeção de $5 \times 10^{6}$ UFC de Enterococcus durans, suspensos em $500 \mu \mathrm{L}$ de SSE, com três repetições.
O inóculo de E. durans ATCC 19492 foi incubado em tubos de ensaio, com meio de cultura líquido LuriaBertani (LB), a $30^{\circ} \mathrm{C}$, por 24 horas. Após esse período, o inóculo foi centrifugado por $15 \mathrm{~min}$ a $10.000 \mathrm{~g}$, e o precipitado ressuspenso em $10 \mathrm{~mL}$ de SSE. Para a contagem de E. durans, presente no inóculo, foram realizadas cinco diluições seriadas fator 1:10, semeadas em placas com meio de cultura TSA, para nova diluição em SSE, a fim de atingir a concentração $1 \times 10^{6} \mathrm{UFC} \mathrm{mL}^{-1}$.

Os peixes foram alimentados duas vezes ao dia, à vontade, durante 14 dias, com ração-controle ou suplementada com a cepa de bactéria ácido-láctica. Após 24 horas de jejum, os peixes foram submetidos às injeções intraperitoneal de SSE ou de E. durans, suspensos em $500 \mu \mathrm{L}$ de SSE e, após 48 horas, foram coletadas as amostras. Durante os 16 dias de experimento, a temperatura da água manteve-se em $23,3 \pm 1,7^{\circ} \mathrm{C}$, o oxigênio dissolvido em $4,1 \pm 0,8 \mathrm{mg} \mathrm{L}^{-1}$ e o $\mathrm{pH} 7,2 \pm 0,7$.

Para a coleta de amostras, nove peixes de cada tratamento foram anestesiados com benzocaína $50 \mathrm{mg} \mathrm{L}^{-1}$ - e cerca de $1 \mathrm{~mL}$ de sangue foi coletado e duplicatas de extensões sangüíneas foram coradas com Giemsa/MayGrunwald (Rosenfeld, 1947), para contagem diferencial de leucócitos e contagens totais de trombócitos e leucócitos. Uma alíquota foi utilizada para a determinação do hematócrito (Goldenfarb et al., 1971), glicose (Accu-Chek Advantage 2 Roche), e o restante foi armazenado em frascos de vidro no gelo, para quantificar o número total de eritrócitos em hemocitômetro. Os números totais de trombócitos e leucócitos foram obtidos na extensão sangüínea pelo método indireto (Martins et al., 2008).

Para as análises estatísticas, os valores das contagens microbiológicas foram transformados para $\log (\mathrm{x}+1)$. Os dados foram submetidos à análise de variância. Uma vez encontrada a diferença entre os tratamentos, as médias foram comparadas, pelo teste StudentNewman-Keuls, a 5\% de probabilidade (Zar, 1986).

\section{Resultados e Discussão}

Das seis cepas isoladas, duas apresentaram os maiores halos de inibição, com média de 15,7 mm (Tabela 1), e foram identificadas como: L. platarum e L. brevis, com 99,9 e 97,4\% de probabilidade, respectivamente.

Neste trabalho, ambas as espécies de Lactobacillus apresentaram inibição semelhante à eritromicina. 
Li et al. (2006) também observaram efeito inibitório de bactérias probióticas semelhante ao antibiótico clorafenicol. Todos os halos produzidos pelas bactérias ácido-lácticas superaram o da oxitetraciclina, que é um dos antibióticos permitidos para uso veterinário e largamente utilizado na aqüicultura (MacMillan, 2001). Segundo Petersen \& Dalsgaard(2003), Enterococcus sp. apresenta resistência à oxitetraciclina e eritromicina, e é uma bactéria considerada boa indicadora de resistência microbiana. Este trabalho permitiu sugerir $V$. harveyi, $V$. anguilarum e $V$. alginolyticus como boas indicadoras de resistência microbiana contra oxitetraciclina por não terem sidos inibidas.

Nas tilápias alimentadas com dieta suplementada com L. plantarum houve menor número de bactérias totais no intestino, em relação à L. brevis $(\mathrm{p}<0,05)$, porém o número de bactéria totais no trato intestinal dos peixes-controle não diferiu em ambos os tratamentos suplementados com bactérias ácido-lácticas $(\mathrm{p}>0,05)$ (Tabela 2).

A contagem de Vibrio ssp. não diferiu entre os tratamentos $(p>0,05)$. E a contagem de bactérias ácido-lácticas, no intestino das tilápias alimentadas com as rações suplementadas com ambos Lactobacillus, foi maior do que nos animais-controle $(\mathrm{p}<0,05)$. Peixes alimentados com $L$. plantarum apresentaram menor $(\mathrm{p}<0,05)$ contagem de Pseudomonas sp. no trato intestinal, o que pode estar associado à capacidade das cepas de bactérias probióticas em inibir o crescimento de bactérias patogênicas, também comprovado por Vieira et al. (2007).

A microbiota bacteriana intestinal de organismos aquáticos, ao contrário dos organismos terrestres, é constituída predominantemente por bactérias gram-negativas (Gómez-Gil et al., 2000), e pode variar de acordo com o ambiente, escassez de algum nutriente ou pelo uso de bactérias probióticas (Gatesoupe, 2008). Em tilápia, os Vibrio ssp. normalmente dominam, porém neste trabalho foi observado que os peixes que receberam ração suplementada com bactérias ácido-lácticas apresentaram uma alteração, e passaram a apresentar grande população de bactérias ácido-lácticas. A redução na contagem de Vibrio sp. pode estar relacionada à capacidade de as bactérias ácido-lácticas, suplementadas à ração, produzirem substâncias inibidoras (Ramírez et al., 2006; Vieira et al., 2007), tais como: substâncias bactericidas de alto (bacteriocinas) e baixo (reuterinas) peso molecular (Fooks \& Gibson, 2002), ácido láctico e ácido acético (Vázquez et al., 2005) e peróxido de hidrogênio (Sugita et al., 2007). Outro possível mecanismo de inibição pode ser a exclusão competitiva por nutrientes e espaço (Gómez-Gil et al., 2000), ou alteração do metabolismo microbiano no intestino (Gatesoupe, 2008).

Não houve alteração na percentagem de hematócrito com os tratamentos. Esse resultado foi semelhante ao de Welker et al. (2007), em tilápias não infectadas experimentalmente, contrariando os resultados de Řehulka (2002), que observou aumento na percentagem de hematócrito de peixes infectados por Aeromonas sobria e A. caviae.

Para os parâmetros hematológicos de contagem totale diferencial dos leucócitos, houve interação significativa $(p<0,05)$ entre os fatores: peixes alimentados com dieta suplementada com L. plantarum e controle; e peixes não submetidos à injeção, peixes submetidos à injeção de $500 \mu \mathrm{L}$ de SSE e peixes submetidos à injeção de $5 \times 10^{6}$ UFC de E. durans suspensos em $500 \mu \mathrm{L}$ de SSE.

Tabela 1. Valores médios dos halos de inibição $(\mathrm{mm})$ de bactérias ácido-lácticas e de antibiogramas contra cepas de bactérias patogênicas $^{(1)}$.

\begin{tabular}{|c|c|c|c|c|c|c|c|}
\hline $\begin{array}{l}\text { Cepas bacteriana }{ }^{(2)} / \\
\text { antibiótico }\end{array}$ & Vibrio harveyi & $\begin{array}{c}\text { Vibrio } \\
\text { anguillarum }\end{array}$ & $\begin{array}{c}\text { Vibrio } \\
\text { alginolyticus }\end{array}$ & Enterococcus sp. & $\begin{array}{l}\text { Micrococcus } \\
\text { luteus }\end{array}$ & $\begin{array}{l}\text { Escherichia } \\
\text { coli }\end{array}$ & Média \\
\hline L. plantarum & $14 \mathrm{c}$ & $14 \mathrm{~b}$ & $14 \mathrm{~b}$ & $18 \mathrm{~b}$ & $19 \mathrm{e}$ & $16 \mathrm{e}$ & 15,7 \\
\hline L. Brevis & $12 d$ & $12 \mathrm{c}$ & $16 \mathrm{a}$ & $12 \mathrm{e}$ & $16 f$ & $18 \mathrm{~d}$ & 15,7 \\
\hline $\mathrm{J} 5$ & $12 d$ & $12 \mathrm{c}$ & $14 b$ & $18 b$ & $20 \mathrm{e}$ & $18 \mathrm{~d}$ & 14,3 \\
\hline J6 & $12 d$ & $12 \mathrm{c}$ & $13 \mathrm{c}$ & $13 \mathrm{e}$ & $20 \mathrm{e}$ & $22 b$ & 15,3 \\
\hline $\mathrm{J} 7$ & $12 d$ & $12 \mathrm{c}$ & $10 \mathrm{~d}$ & $14 d$ & $16 f$ & $16 \mathrm{e}$ & 13,2 \\
\hline $\mathrm{J} 8$ & $12 d$ & $12 \mathrm{c}$ & $15 b$ & $13 \mathrm{e}$ & $22 d$ & $20 \mathrm{c}$ & 15,6 \\
\hline Magnemicina & $20 \mathrm{a}$ & $14 \mathrm{~b}$ & $14 b$ & $21 \mathrm{a}$ & $38 \mathrm{a}$ & $14 \mathrm{f}$ & 20,2 \\
\hline Eritromicina & $15 \mathrm{~b}$ & $16 \mathrm{a}$ & $16 \mathrm{a}$ & $18 \mathrm{~b}$ & $34 b$ & $16 \mathrm{e}$ & 19,2 \\
\hline Enrofloxacina & $10 \mathrm{e}$ & $12 d$ & $10 \mathrm{~d}$ & $16 \mathrm{c}$ & $26 \mathrm{c}$ & $24 \mathrm{a}$ & 16,3 \\
\hline Oxitetraciclina & of & $0 \mathrm{e}$ & $0 \mathrm{e}$ & of & $34 b$ & $20 c$ & 9,0 \\
\hline
\end{tabular}

${ }^{(1)}$ Médias seguidas de letras iguais, na coluna, não diferem entre si pelo teste Student-Newman-Keuls, a 5\% de probabilidade. ${ }^{(2)}$ J5, J6, J7 e J8: cepas de bactérias ácido-lácticas não identificadas. 
Tanto o número de eritrócitos quanto o total de trombócitos foi maior $(\mathrm{p}<0,05)$ em animais alimentados com L. plantarum e submetidos à injeção de $E$. durans (Tabela 3). Possivelmente, a suplementação com probiótico favoreceu à maior produção dessas células em resposta à infecção, e não deixou que a infecção afetasse a hematopoiese (Barham et al., 1980). A adição de L. plantarum na ração deve ter estimulado a produção de trombócitos quando os peixes foram infectados experimentalmente com E. durans. Além de aglutinação, essas células estão envolvidas na defesa e na resposta inflamatória (Matushima \& Mariano, 1996). Barham et al. (1980) e Řehulka (2002) observaram menores valores de eritrócitos para peixes infectados com Aeromonas sp., em trutas, diferentemente do observado neste trabalho, em que os peixes alimentados com ração-controle e infectados experimentalmente com E. durans obtiveram os mesmos valores do tratamento em que os peixes não foram infectados. Esses dados corroboram os de Harikrishnan et al. (2003) e Martins et al. (2008) com carpas e tilápias infectadas por Aeromonas hydrophila e Enterococcus sp., respectivamente.

Os peixes alimentados com L. plantarum e submetidos à injeção de SSE e E. durans apresentaram os maiores $(\mathrm{p}<0,05)$ totais de leucócitos comparados aos demais (Tabela 3). Este resultado corroborou os observados por Pathiratne \& Rajapakshe (1998), em Etroplus suratensis, infectados pela síndrome ulcerativa epizoótica, e Harikrishnan (2003), em carpas comum, infectadas com $A$. hydrophilla. Por sua vez, dieta-controle, peixes submetidos à injeção de SSE e E. durans apresentaram os menores números dessas células. A redução nos totais de leucócitos, nos animais alimentados com dieta-controle e submetidos à infecção de $E$. durans, está de acordo com o relatado por Garcia et al. (2007), em juvenis de tambaqui infectados experimentalmente com A. hydrophila. Essa redução pode estar relacionada à migração de células para o sítio inflamado.

$\mathrm{Na}$ contagem diferencial de leucócitos, os peixes alimentados com ração suplementada com $L$. plantarum e não submetidos à injeção e os submetidos à injeção de $E$. durans apresentaram os maiores números de linfócitos circulantes. Mais uma vez, os números de neutrófilos e de monócitos foram significativamente maiores após a alimentação com $L$. plantarum e à injeção de E. durans (Tabela 3).

Pathiratne \& Rajapakshe (1998) observaram que ciclídeos, infectados pela síndrome ulcerativa

Tabela 2. Contagens bacterianas no intestino de tilápias-do-nilo alimentadas com ração comercial não suplementada (controle), ração suplementada com Lactobacillus plantarum e com Lactobacillus brevis ${ }^{(1)}$.

\begin{tabular}{|c|c|c|c|c|}
\hline \multirow[t]{2}{*}{ Tratamento } & \multicolumn{4}{|c|}{ Contagem bacteriana $\left(\log \mathrm{UFC} \mathrm{mL}^{-1}\right)$} \\
\hline & Bactérias totais & Bactérias ácido-lácticas & Vibrio ssp. & Pseudomonas ssp. \\
\hline Controle & $7,68 \pm 0,98 \mathrm{ab}$ & $2,66 \pm 0,42 b$ & $5,36 \pm 0,95 a$ & $3,81 \pm 0,21 \mathrm{a}$ \\
\hline Ração com L. plantarum & $6,35 \pm 0,87 b$ & $5,60 \pm 1,36 \mathrm{a}$ & $5,38 \pm 0,32 \mathrm{a}$ & $1,60 \pm 1,94 b$ \\
\hline Ração com L. brevis & $8,06 \pm 0,94 \mathrm{a}$ & $6,31 \pm 0,62 \mathrm{a}$ & $5,52 \pm 1,34 \mathrm{a}$ & $4,83 \pm 0,56 \mathrm{a}$ \\
\hline
\end{tabular}

${ }^{(1)}$ Médias \pm erro-padrão seguidas de letras iguais, na coluna, não diferem entre si pelo teste Student-Newman-Keuls, a $5 \%$ de probabilidade; dados transformados para $\log (\mathrm{x}+1)$.

Tabela 3. Parâmetros hematológicos em tilápias-do-nilo alimentadas ou não com ração suplementada com Lactobacilus plantarum e infectadas ou não com Enterococcus durans ${ }^{(1)}$.

\begin{tabular}{|c|c|c|c|c|c|c|c|c|}
\hline Tratamento & $\begin{array}{l}\text { Glicose } \\
\left(\mathrm{mg} \mathrm{dL}^{-1}\right)\end{array}$ & $\begin{array}{l}\text { Eritrócitos } \\
\left(\mathrm{x} 10^{6} \mu \mathrm{L}^{-1}\right)\end{array}$ & $\begin{array}{l}\text { Trombócitos } \\
---\left(x 10^{3}\right. \\
\end{array}$ & $\begin{array}{l}\text { Leucócitos } \\
\left.\mathrm{LL}^{-1}\right)-\end{array}$ & $\begin{array}{c}\text { Hematócrito } \\
(\%)\end{array}$ & Linfócitos & $\begin{array}{l}\text { Neutrófilos } \\
-\left(\mathrm{x} 10^{3} \mu \mathrm{L}^{-1}\right)-\end{array}$ & Mor \\
\hline $\begin{array}{l}\text { ieta-controle e peixe não } \\
\text { bmetido à injeção }\end{array}$ & $96,3 \pm 44,9 a$ & $46 \pm 0,03 b$ & $35,4 \pm 3,1 b$ & $13,7 \pm 1,6 b c$ & & $6,63 \pm 0,70 \mathrm{~b}$ & & $0,24 \pm 0,2$ \\
\hline $\begin{array}{l}\text { L. plantarum e peixe } \\
\text { tido à injeção }\end{array}$ & $150,3 \pm 11,3 \mathrm{a}$ & $1,15 \pm 0,05 \mathrm{~b}$ & $28,0 \pm 1,9 b$ & $15,1 \pm 1,6 a b c$ & $30,8 \pm 2,9 a$ & $12,47 \pm 1,41 \mathrm{a}$ & $6,47 \pm 0,24 b$ & $0,66 \pm 0,04 b$ \\
\hline njeçã & $106,6 \pm 29,5 \mathrm{a}$ & $1,18 \pm 0,08 b$ & $26,9 \pm 1,9 b$ & $12,0 \pm 1,6 \mathrm{c}$ & $26,5 \pm 2,9 a$ & $5,33 \pm 1,13 b$ & $6,38 \pm 0,53 b$ & $0,05 \pm 0,01 b$ \\
\hline subm & $58,4 \pm 4,4 \mathrm{a}$ & $1,26 \pm 0,09 b$ & $30,6 \pm 3,6 b$ & $20,1 \pm 3,1 \mathrm{ab}$ & $29,7 \pm 3,4 \mathrm{a}$ & $7,98 \pm 1,93 b$ & $6,85 \pm 0,91 b$ & $0,08 \pm 0,03 b$ \\
\hline injeçã & $59,3 \pm 9,5 \mathrm{a}$ & $1,42 \pm 0,10 \mathrm{~b}$ & $36,2 \pm 3,9 b$ & $10,9 \pm 1,6 \mathrm{c}$ & $33,3 \pm 2,0 \mathrm{a}$ & $7,53 \pm 1,25 b$ & $4,40 \pm 0,87 \mathrm{c}$ & $0,73 \pm 0,24 b$ \\
\hline & $63,2 \pm 8,3 \mathrm{a}$ & $1,96 \pm 0,13 \mathrm{a}$ & $47,4 \pm 1,4 \mathrm{a}$ & $22,3 \pm 1,4 \mathrm{a}$ & $25,1 \pm 2,1 \mathrm{a}$ & $15,39 \pm 0,99 \mathrm{a}$ & $8,85 \pm 0,39 a$ & $1,47 \pm 0,24 \mathrm{a}$ \\
\hline
\end{tabular}

${ }^{(1)}$ Médias \pm erro-padrão seguidas de letras iguais não diferem entre si pelo teste Student-Newman-Keuls, a 5\% de probabilidade; SSE: solução salina estéril. 
epizoótica, apresentaram aumento no número de neutrófilos, contrariamente ao observado neste trabalho, em que os animais alimentados com dieta-controle e não submetidos à injeção, e peixes alimentados com ração suplementada com $L$. plantarum e submetidos à infecção de $E$. durans não divergiram nos valores. Carneiro et al. (2002) ressalta que o aumento no número dessas células pode ser indicador de estresse, juntamente com outros parâmetros.

A contagem de monócitos foi superior nos peixes do tratamento que recebeu dieta suplementada com L. plantarum e submetidos à infecção de E. durans. Resultado semelhante foi encontrado por Aly et al. (2008) com tilápias, em que o número de monócitos, a atividade fagocitária e a atividade da lisozima foi superior nos peixes alimentados com dieta suplementada com Lactobacillus acidophilus. Kumar et al. (2008) também observaram aumento na contagem de monócitos em Labeo rohita, alimentado com Bacillus subtillis após uma infecção com $A$. hydrophila. Estes resultados sugerem que a dieta suplementada com esses probióticos pode melhorar a resposta do sistema imune inespecífica do hospedeiro.

As tilápias alimentadas com ração com L. plantarum apresentaram aumento significativo nos totais de leucócitos $\left(19,19 \pm 1,51 \times 10^{3}\right.$ cel $\left.\mu \mathrm{L}^{-1}\right)$ e linfócitos $\left(17,13 \pm 1,31 \times 10^{3}\right.$ cel $\left.\mu \mathrm{L}^{-1}\right)$ circulantes, em relação aos peixes do tratamento-controle $-12,23 \pm 0,93 \times 10^{3}$ cel $\mu \mathrm{L}^{-1}$ e $10,93 \pm 0,65 \times 10^{3}$ cel $\mu \mathrm{L}^{-1}$, para leucócitos e linfócitos respectivamente. Assim, o maior número de leucócitos totais nos peixes alimentados com ração suplementada com L. plantarum, além de sua capacidade de colonizar e alterar a microbiota intestinal sugere seu efeito probiótico. Diferentemente, Kumar et al. (2008) observam redução no número de linfócitos para L. rohita, alimentado com $B$. subtillis após infecção com A. hydrophila. Welker et al. (2007) não observaram diferença no número de leucócitos circulantes em tilápias-do-nilo, alimentadas com diferentes doses de lactoferrina bovina e infectadas com A. hydrophila.

Aly et al. (2008) não observaram diferenças no hematócrito em tilápias alimentadas com $B$. subtilis e L. acidophilus, assim como neste trabalho. A não alteração da taxa de glicose e do hematócrito nos peixes alimentados com $L$. plantarum indica que todos os animais sofreram o mesmo efeito do estresse provocado pelo manejo da injeção.

A suplementação de probiótico (L. plantarum) na ração pode ter induzido a maior produção ou liberação de leucócitos totais e de linfócitos circulantes, fato que pode ser interessante para a resposta inespecífica em relação às infecções. Mesmo sem entrar em contato com o sistema sanguíneo do hospedeiro, as bactérias ácido-lácticas podem interagir diretamente com as células imunes, através de células especializadas do epitélio do intestino, como as células-M, e induzir a ativação e a multiplicação das células responsáveis pela defesa (Gill, 2003).

\section{Conclusões}

1. As cepas de Lactobacillus platarum e L. brevis isoladas do intestino de tilápia-do-nilo têm potencial probiótico.

2. A cepa de L. plantarum isolada possui efeito probiótico, pois inibi bactérias patogênicas, coloniza o trato intestinal e melhora a resposta inespecífica do sistema imune de tilápia-do-nilo.

3. O uso de L. plantarum é uma forma de controle preventivo de enfermidades bacterianas.

\section{Agradecimentos}

Ao Conselho Nacional de Desenvolvimento Científico e Tecnológico, pela bolsa de produtividade em pesquisa; a Roberto Hoppe, da Fundação 25 de Julho, em Joinville, SC, pela doação dos peixes; ao Professor Elpídio Beltrame (in memoriam), pela dedicação ao grupo deste trabalho.

\section{Referências}

ALY, S.M.; AHMED, Y.A.; GHAREEB, A.A.; MOHAMED, M.F. Studies on Bacillus subtilis and Lactobacillus acidophilus, as potential probiotics, on the immune response and resistance of tilapia nilotica (Oreochromis niloticus) to challenge infections. Fish and Shellfish Immunology, v.25, p.128-136, 2008.

BARHAM, W.T.; SMIT, G.L.; SCHOOMBEE, H.J. The haematological assessment of bacterial infection in rainbow trout, Salmo gairdneri Richardson. Jornal of Fish Biology, v.17, p.275-281, 1980 .

BOYD, C.E.; MASSAUT, L. Risks associated with the use of chemicals in pond aquaculture. Aquaculture Engineering, v.20, p.113-132, 1999.

CARNEIRO, P.C.F.; MARTINS, M.L.; URBINATI, E.C. Effect of sodium chloride on physiological response and the gill parasite, Piscinoodinium sp., in matrinxã, Brycon cephalus (Teleostei: Characidae) subjected to transport stress. Journal of Aquaculture Tropical, v.17, p.337-348, 2002.

FOOKS, L.J.; GIBSON, G.R. Probiotics as modulators of the gut flora. British Journal of Nutrition, v.88, p.39-49, 2002. (Suplement 1). 
FULLER, R. Probiotics in man and animal. Journal of Applied Bacteriology, v.66, p.365-378, 1989.

GARCIA, F.; PILARSKI, F.; ONAKA, E.M.; MORAES, F.R. de; MARTINS, M.L. Hematology of Piaractus mesopotamicus fed diets supplemented with vitamins $\mathrm{C}$ and $\mathrm{E}$, challenged by Aeromonas hydrophila. Aquaculture, v.271, p.39-46, 2007.

GATESOUPE, F.J. The use of probiotics in aquaculture. Aquaculture, v.180, p.147-165, 1999.

GATESOUPE, F.J. Updating the importance of lactic acid bacteria in fish farming: natural occurrence and probiotic treatments. Journal of Molecular Microbiology and Biotechnology, v.14, p.107-114, 2008.

GILL, H.S. Probiotics to enhance anti-infective defenses in the gastrointestinal tract. Best Practice and Research Clinical Gastroenterology, v.17, p.755-773, 2003.

GOLDENFARB, P.B.; BOWYER, F.P.; HALL, E.; BROSIUS, E. Reproductibility in the hematology laboratory: the microhematocrit determination. American Journal of Clinical Pathology, v.56, p.35-39, 1971.

GOMEZ-GIL, B.; ROQUE, A.; TURNBULL, J.F. The use and selection of probiotic bacteria for use in the culture of larval aquatic organisms. Aquaculture, v.191, p.259-270, 2000.

HARIKRISHNAN, R.; NISHA RANI, M.; BALASUNDARAM, C. Hematological and biochemical parameters in common carp, Cyprinus carpio, following herbal treatment for Aeromonas hydrophila infection. Aquaculture, v.221, p.41-50, 2003.

KUMAR, R.; MUKHERJEE S.C.; RANJAN, R.; NAYAK, S.K. Enhanced innate immune parameters in Labeo rohita (Ham.) following oral administration of Bacillus subtilis. Fish and Shellfish Immunology, v.24, p.168-172, 2008.

LI, J.; TAN, B.; MAI, K.; AI, Q.; ZHANG, W.; XU, W.; LIUFU, Z.; MA, H. Comparative study between probiotic bacterium Arthrobacter XE-7 and chloramphenicol on protection of Penaeus chinensis post-larvae from pathogenic vibrios. Aquaculture, v.253, p.140-147, 2006.

MACMILLAN, J.R. Aquaculture and antibiotic resistance: Anegligible public health risk? World Aquaculture, v.32, p.49-50, 2001.

MARTINS, M.L.; MOURIÑO, J.L.P.; AMARAL, G.V.; VIEIRA, F.N.; DOTTA, G.; JATOBÁ, A.; PEDROTTI, F.S.; JERÔNIMO, G.T.; BUGLIONE NETO, C.C.; PEREIRA JUNIOR, G. Haematological changes in Nile tilapia experimentally infected with Enterococcus sp. Brazilian Journal of Biology, v.68, p.631-637, 2008.

MATUSHIMA, E.R.; MARIANO, M. Kinetics of the inflammatory reaction induced by carrageenin in the swimbladder of Oreochromis niloticus (Nile tilapia). Brazilian Journal of Veterinary Research and Animal Science, v.33, p.5-10, 1996.

MORAES, F.R.; MARTINS, M.L. Condições predisponentes e principais enfermidades de teleósteos em piscicultura intensiva. In: CYRINO, J.E.P.; URBINATI, E.C.; FRACALOSSI, D.M.; CASTAGNOLLI, N. (Ed.). Tópicos especiais em piscicultura de água doce tropical intensiva. São Paulo: TecArt, p.343-383, 2004.

PATHIRATNE, A.; RAJAPAKSHE, W. Hematological changes associated with epizootic ulcerative syndrome in the Asian cichlid fish, Etroplus suratensis. Asian Fisheries Science, v.11, p.203-211, 1998.

PETERSEN, A.; DALSGAARD, A. Antimicrobial resistance of intestinal Aeromonas spp. and Enterococcus spp. in fish cultured in integrated broiler-fish farms in Thailand. Aquaculture, v.219, p.71-82, 2003.

PLANAS, M.; CUNHA, I.; MUNILLA, R. Utilización de antibióticos para la mejora del cultivo larvario del rodaballo con fines experimentales. In: CASTELLO, F.; CALDERER, A. (Ed.). Proceedings of the Fifth National Congress on Aquaculture. San Carles de la Rápita: Universitat de Barcelona, 1994. p.765-770.

PLUMB, J.A. Health maintenance and principal microbial diseases of cultured fishes. $2^{\text {nd }}$ ed. Ames: Iowa State University, 1999. 328p.

RAMÍREZ, C.; BOLÍVAR, A.; CIFFONI, G.A.; PANCHENIAK, E.M.G.; SOCCOL, E.F.R.C. Microorganismos lácticos probióticos para ser aplicados en la alimentación de larvas de camarón y peces como substituto de antibiótico. La Alimentación Latino Americana, v.264, p.70-78, 2006.

ŘEHULKA, J. Aeromonas causes severe skin lesions in rainbow trout (Oncorhynchus mykiss): clinical pathology, haematology and biochemistry. Acta Veterinaria Brno, v.71, p.351-360, 2002.

ROSENFELD, G. Corante pancrômico para hematologia e citologia clínica. Nova combinação dos componentes do May-Grünwald e do Giemsa num só corante de emprego rápido. Memórias do Instituto Butantan, v.20, p.329-334, 1947.

SHOEMAKER, C.A.; KLESIUS, P.H. Streptococcal disease problems and control: a review. In: FITZSIMMONS, K. (Ed.). Tilapia Aquaculture. Ithaca: Northeast Regional Agricultural Engineering Service, 1997. v.2. p.671-680.

SUGITA, H.; OHTA, K.; KURUMA, A.; SAGESAKA, T. An antibacterial effect of Lactococcus lactis isolated from the intestinal tract of the Amur catfish, Silurus asotus, Linnaeus. Aquaculture Research, v.38, p.1002-1004, 2007.

TAGG, J.R.; McGIVEN, A.R. Assay system for bacteriocins. Applied Microbiology, v.21, p.943, 1971.

VÁZQUEZ, J.A.; GONZÁLEZ, M.P.; MURADO, M.A. Effects of lactic acid bacteria cultures on pathogenic microbiota from fish. Aquaculture, v.245, p.149-161, 2005.

VERSCHUERE, L.; ROMBAUT, G.; SORGELOOS, P.; VERSTRAETE, W. Probiotic bacteria as biological control agents in aquaculture. Microbiology and Molecular Bioliology Reviews, v.64, p.655-671, 2000.

VIEIRA, F. do N.; PEDROTTI, F.S.; BUGLIONE, C.C.; MOURIÑO, J.L.P.; BELTRAME, E.; MARTINS, M.L.; RAMIRES, C.; VINATEA ARANA, L.A. Lactic-acid bacteria increase the survival of marine shrimp, Litopenaeus vannamei, after infection with Vibrio harveyi. Brazilian Journal of Oceanography, v.55, p.251-255, 2007.

WELKER, T.L.; LIM, C.; YILDIRIM-AKSOY, M.; KLESIUS, P.H. Growth, immune function, and disease and stress resistance of juvenile Nile tilapia (Oreochromis niloticus) fed graded levels of bovine lactoferrin. Aquaculture, v.262, p.156-162, 2007.

ZAR, J.H. Biostatistical analysis. $3^{\text {rd }}$ ed. Upper Saddle River: Prentice Hall, 1996. 718p.

Recebido em 9 de fevereiro de 2008 e aprovado em 29 de agosto de 2008

Pesq. agropec. bras., Brasília, v.43, n.9, p.1201-1207, set. 2008 
